\title{
OS PAPÉIS DE GÊNERO NOS LIVROS DIDÁTICOS DE CIÊNCIAS
}

\author{
Eliecília de Fátima Martins \\ Universidade Salgado de Oliveira e Rede Municipal de Ensino de Goiânia \\ eliecilia@ibest.com.br \\ Zara Hoffmann \\ Professora de Química do IQ / Universidade Federal de Goiás \\ z.quimica@gmail.com
}

\begin{abstract}
RESUMO
Este trabalho realiza uma leitura sobre as identidades de gênero nos livros didáticos de Ciências, da primeira fase do ensino fundamental, discutindo as invenções identitárias apresentadas. Analisa a divisão do mundo do homem e do mundo da mulher, buscando demonstrar como os discursos dessas obras reafirmam a matriz bipolar "masculino" e "feminino" nas relações de gênero. Descreve e problematiza o funcionamento das mensagens subliminares que procuram produzir identidades distintas entre homens e mulheres por meio de uma sexualização dos espaços doméstico e do mercado de trabalho. Em geral, os livros didáticos reproduzem uma separação espacial que captura homens e mulheres em territórios opostos, disponibilizando uma hierarquia sócio-econômica entre eles.
\end{abstract}

Palavras-Chave: gênero, livro didático, papéis sexuais.

\section{THE GENDER'S PAPERS ON SCIENCES DIDACTIC BOOKS}

\begin{abstract}
This work accomplishes a reading on gender identities on Sciences didactic books used in first phase of basic education, arguing the presented identitarian inventions. It analyzes the division of the world of the man and the world of the woman, searching to demonstrate how the speeches of these book reaffirm the "masculine" and "feminine" bipolar model in gender relations. It describes and problematizes the functioning of subliminar messages that try to produce distinct identities between men and women by means of a sexualization of the domestic spaces and trade market. In general, didactic books reproduce a spacial division that capture men and women in opposing territories, providing a social and an economic hierarchy between them.
\end{abstract}

Key-words: gender, didactic book, sexual papers 


\section{INTRODUÇÃO}

A segregação sexual inicia-se antes do nascimento, no seio da família, por meio de suas concepções, valores, pudores e vivências. É um aprendizado contínuo, pelo qual a criança assume comportamentos na esfera da sexualidade, desempenhando um papel sexual (SPENCE, 1993).

Os papéis sexuais estão relacionados ao conceito de gênero discutido por Scott, que o entende tanto como símbolos culturalmente disponíveis que evocam representações, muitas delas contraditórias, quanto como conceitos normativos que tomam, comumente, uma oposição binária entre masculino e feminino. Indo além da idéia binária de dois sexos e dois gêneros, Scott (1991), Louro (1998) e Casagrande (2005) também compreendem gênero numa perspectiva relacional, como categoria política e histórica.

Este trabalho tomou como objeto de estudo dos papéis sexuais, o livro didático de Ciências, da $1^{\text {a }}$ e $2^{\mathrm{a}}$ série (ciclo I) do Ensino Fundamental. A infância é o período de construção de conceitos e valores e, segundo Spence (1993) e Graciano (1978), os indivíduos nessa fase estão em processo de formação de sua identidade, incluindo a questão da sexualidade. Por sua vez, o livro didático pode ser eficaz na transmissão cultural e constituir-se em elemento de influência na formação e transformação da identidade dos estudantes (NOSELLA, 1979). Partiu-se de uma amostra de 44 obras, selecionadas dentre as vinte e quatro coleções aprovadas pela avaliação do PNLD/2004 (Plano Nacional do Livro Didático).

A questão da sexualidade, mesmo que numa perspectiva restrita e biológica, historicamente faz parte do currículo da área de Ciências. Atualmente, as orientações propostas nos Parâmetros Curriculares Nacionais (PCNs), traz o assunto como tema transversal, perpassando em todas as disciplinas. Em Ciências, especificamente no bloco temático "Ser Humano e Saúde", é proposta a discussão sobre sexualidade e o respeito às diferenças entre as pessoas e entre os sexos.

Desse modo, destacam-se para estudo as seguintes questões: quais são os papéis de gênero considerados apropriados pelos livros? As mensagens presentes nos mesmos questionam ou reproduzem os papéis socialmente aceitos para homens e mulheres?

A partir destes questionamentos, verificou-se a presença e a ausência de manifestação de sexismo, de estimulação ou não da eqüidade entre homens e 
mulheres, analisando e interpretando a maneira como as obras referem-se aos homens e às mulheres e os papéis que lhes são atribuídos.

Para a análise do conteúdo dos livros partiu-se do pressuposto de Hall (1990) de que a interpretação que os leitores fazem dessas obras não é um processo mecânico. Para Biocca (1988), em função dos livros não mostrarem uma representação completa de todas as possibilidades de comportamento, as mensagens dominantes podem prevalecer. Currie $(1999$, p. 17) completa essa idéia ao dizer que "as mensagens que se encontram apoiadas pelo consenso social têm um poder maior de influenciar os leitores".

O trabalho foi dividido em três categorias principais. Na primeira, refere-se ao comportamento de menina e de menino, discutida pelo estudo do look de cada um, criado a partir das vestimentas, suas cores, estampas e acessórios, e do estudo das brincadeiras e atividades cotidianas. A segunda trata do papel do homem e do papel da mulher no processo produtivo, por meio da análise do trabalho, remunerado ou não, atribuído aos dois gêneros. Na última categoria, analisam-se exemplos significativos dos papéis de gênero atribuídos aos homens e às mulheres dentro do contexto social e cultural da nossa época.

\section{COMPORTAMENTO DE MENINA E COMPORTAMENTO DE MENINO}

A construção do masculino e do feminino é mediada pela cultura, a qual é articulada através da linguagem escrita, falada e simbólica (HALL 2002). Os papéis sociais podem ser reforçados pelas ilustrações, através da diferenciação nas roupas e nas brincadeiras de meninos e meninas. A partir da designação de tarefas específicas e condutas distintas nesta relação, os livros tendem a mostrar uma visão estereotipada sobre os papéis socialmente aceitos e recomendados para cada gênero.

\section{As Roupas de Meninos e as Roupas de Meninas.}

Os resultados mostram dados obtidos na análise dos livros, mas não são exclusivos, isto é, as obras que apresentam meninas com vestimentas cor-de-rosa, apresentam também, meninas vestidas em outras cores. No entanto para os cabelos, os dados valem para todas as meninas e para todos os meninos presentes no livro. 
A partir do estudo das vestimentas como diferenciador de gênero, obteve-se o gráfico 01, o qual mostra os looks de ambos os gêneros infantis, analisados pelo ato de se arrumar, cor e estampas da roupa (corações ou florzinhas para meninas, listas e animais para meninos), acessórios (tiaras, laços prendedores de cabelos, bonés e sapatos).

Gráfico 01. Look das meninas e dos meninos (amostra de 44 livros)

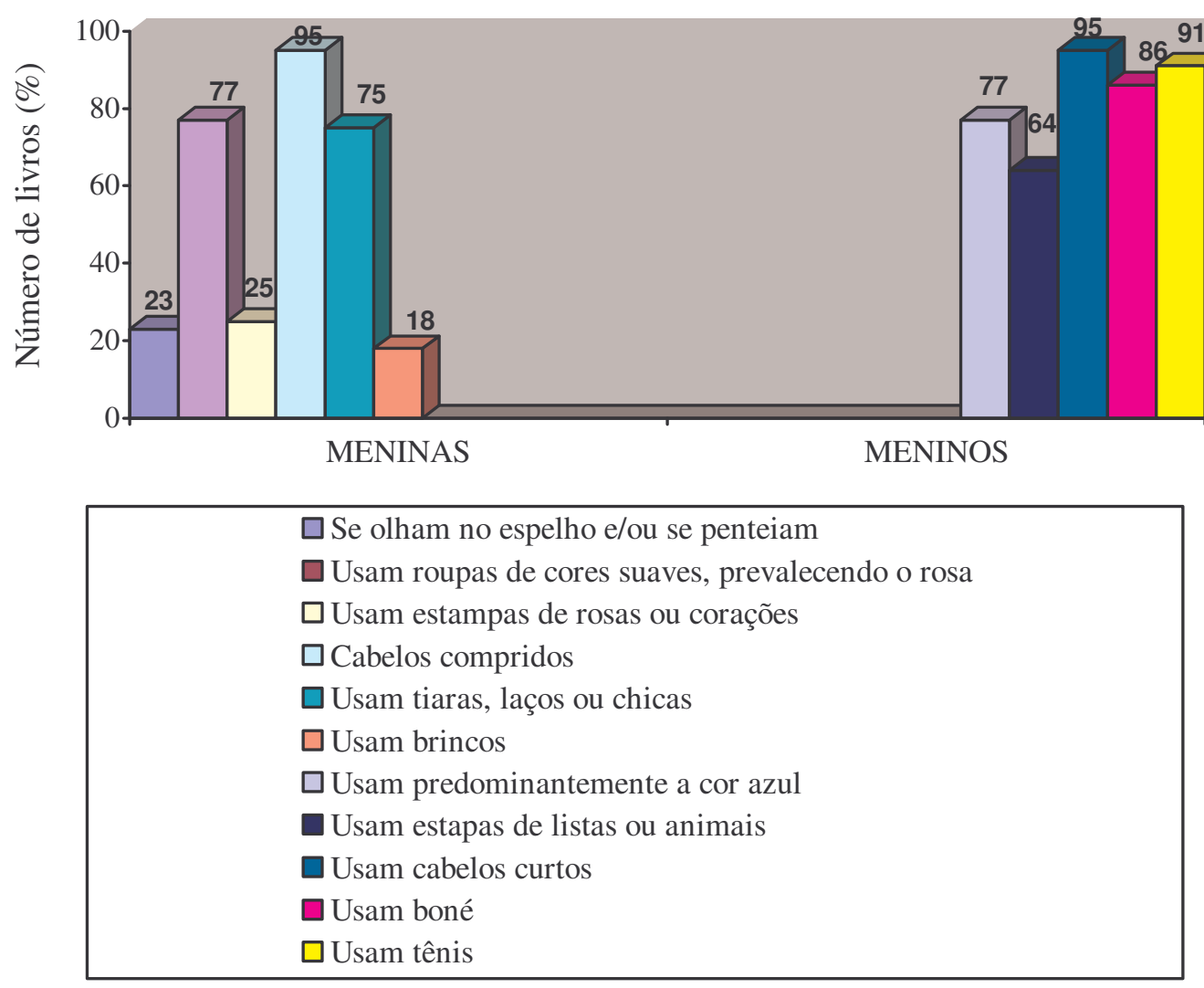

A vestimenta é uma das mais importantes linguagens não verbalizadas. Por meio dela as pessoas se comunicam e se integram socialmente. Mas também é um instrumento de controle e exclusão social, um dispositivo orientado pelo comportamento mediante ao que é cultural e socialmente aceito (BAUDRILLARD, 1996, p.21). Nesse sentido, Embacher (2003, p.42) afirma que "o vestuário participa da constituição da identidade e é por ela constituído. O indivíduo, ao construir seu próprio estilo, cria uma identidade, que articula as igualdades e as diferenças" desenvolvidas pela história desse mesmo indivíduo.

Os livros podem estar contribuindo para determinar comportamentos por meio da diferenciação das roupas de meninos e de meninas, transmitindo a forma 
"adequada" como cada sexo deve se vestir e agir. As meninas se vestem com roupas em tons claros e suaves de rosa, lilás ou amarelo (77\%), ou com pequenas estampas florais ou contendo corações (25\%).

Pode-se exemplificar a seguinte situação em uma das obras: a menina apresenta-se vestida na cor rosa, florzinha bordada no bolso, cabelos longos e segurando um regador pintado com florzinhas. Ela rega, por incrível que pareça, outra florzinha. Essas "florzinhas" simbolizam a idéia de que a mulher é um ser delicado, suave e frágil. Já o menino, apresenta-se de boné, bermuda azul, soltando pipa e correndo livre.

Em outra obra é apresentada uma menina ainda bebê, engatinhando na direção de um gatinho. Tem os cabelos presos por "chiquinhas" rosa, usa meias rosa, bermuda azul claro, blusa rosa estampada com florzinhas, um brinco de bolinha e, finalizando o look, na boca um bico rosa.

A partir dos looks criados, observa-se que as meninas se apresentam mais vaidosas e arrumadas (23\%) - várias ilustrações têm em comum uma menina olhandose no espelho, penteando os cabelos. Para elas, os enfeites e os adornos são imprescindíveis: usam laços ou tiaras nos cabelos $(75 \%)$ e brincos na orelha (18\%). Os meninos se vestem de azul (77\%), com listas, estampas de bolas de futebol ou de animais selvagens (64\%), boné na cabeça, tênis ou sapatos fechados (86\%). Sparti (1995, p.12) destaca que a vaidade e a fragilidade foram consideradas características "naturalmente" femininas enquanto agressividade e coragem, foram denominadas "naturalmente" masculinas. O mito da "natural" superioridade masculina contraposto à "natural" inferioridade feminina, lembra Graciano (1975), era elaborado em termos de diferenças biológicas.

Quando se fala em cores e seus significados, dois são os focos a serem abordados: o que elas representam para nós e o que podem representar para os outros. Considerando as vestimentas presentes nos livros, podemos buscar o nível simbólico representado pelas suas cores.

As cores evocam símbolos culturais, morais e religiosos. Para Feijó (2005), na era pré-cristã, os recém-nascidos do sexo masculino eram vestidos com roupas azuis, na crença de que ficariam protegidos dos maus espíritos. As meninas eram vestidas com cores associadas à fertilidade, como o preto da cultura oriental. Já no Século XIX, na França, associava-se às meninas a cor azul, significando a pureza da Virgem Maria. Nesse mesmo século, a partir de uma lenda européia na qual se dizia que as 
meninas nasciam de rosas e os meninos de repolhos azuis, a cor rosa passou a ser associada à feminilidade, simbolizando as características que devem estar presentes na mulher, como delicadeza, ternura e suavidade.

Essa simbologia das cores, em relação aos gêneros nos livros didáticos de Ciências, arremete à sociedade a construção do papel sexual feminino e do masculino, através de representação cultural de um ideal de mulher e de homem.

A cor rosa é feminina, é o vermelho despido de sua raiva e de seu erotismo. Simbolicamente é a cor do "amor puro", da emoção suave, da doação por excelência; é semelhante ao adoçar. Também é a cor do ato sexual procriador, com amor e responsabilidade da criação, traduz amizade, bondade e pureza de coração. O azul faz parte do universo masculino, está ligado ao céu, ao mar e ao infinito. Reflete confiança e respeito, simbolizando civilidade, poder, status social, tradição e estabilidade; pertence ao mundo físico do trabalho e da autoridade (FISCHERMIRKIN, 2001, p.42). Mas, o mundo, bipolarizado em feminino e masculino, não é tudo isso que representa essas cores, e nem é só isso.

Está implícita, a partir da cor azul, a definição de que "homem que é homem" não usa rosa, brincos, cabelos longos - caso contrário sai da heterossexualidade para a homossexualidade. Assim lhe é negado o direito de também ter características como suavidade, maciez, bondade, delicadeza, generosidade, entre outras. Do mesmo modo, a essência calmante, aconchegante do rosa, simboliza a mulher, mãe, delicada, frágil, passiva... Tira-lhe o direito de tomada de decisão e igualdade no sistema político e produtivo.

Algumas obras tentam sair dos padrões das vestimentas mostrando as meninas com um visual mais esportivo e despojado, usando macacões azuis, calças e camisetas esportivas $(30 \%)$ e os meninos com camisetas na cor rosa (18\%). Percebe-se nas mesmas, o início da mudança do conceito de gênero ligado à idéia binária, a qual reforça as dicotomias rígidas entre homem e mulher para a categoria relacional discutida por Scott (1991).

\section{Brincadeiras de Meninos e Brincadeiras de meninas}

$\mathrm{Na}$ análise das brincadeiras e atividades infantis, também são percebidas a distinção entre brinquedos e brincadeiras de menino e brinquedos e brincadeiras de menina. O gráfico 02 mostra os resultados da análise a esse respeito. 
Gráfico 02. Brincadeiras e atividades de meninos e de meninas (amostra de 44 livros)

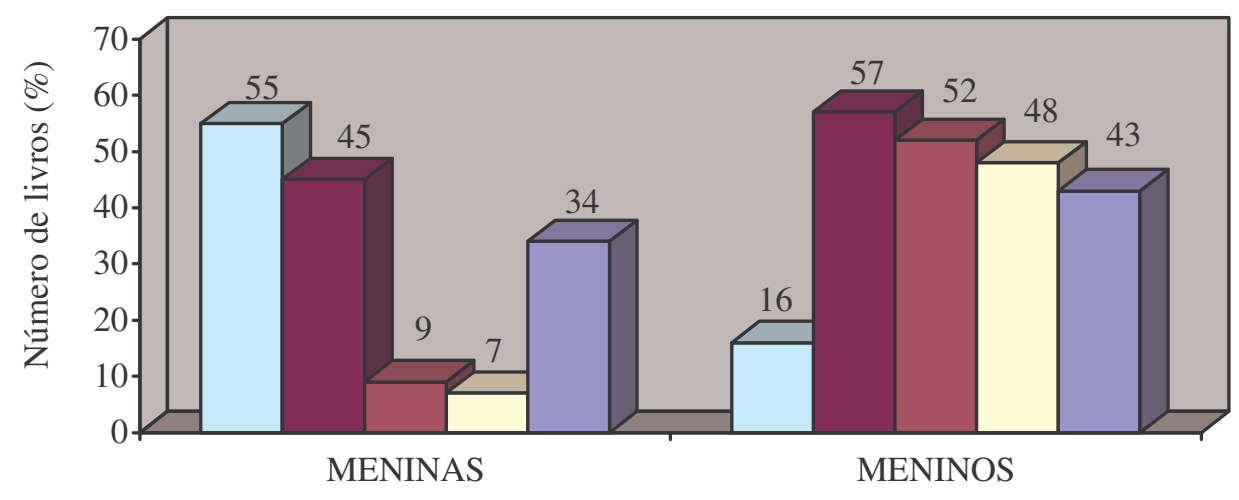

\begin{tabular}{|l}
$\square$ Brincadeiras e atividades voltadas para serviços do lar \\
$\square$ Brincadeiras externas \\
$\square$ Atividades esportivas \\
$\square$ Travessuras \\
$\square$ Atividades intelectuais
\end{tabular}

Nos exemplos de algumas obras, as brincadeiras e atividades realizadas pelas meninas estão voltadas para as tarefas do lar (55\%). Elas brincam com boneca, panelinha, bichos de pelúcia. Também cozinham, lavam louça, lavam e passam roupa, cuidam dos afazeres domésticos e das crianças menores da casa. Em atividades externas ao lar (45\%), vão à praia, à praça, brincam de jogos e pulam corda. Em atividades e/ou brincadeiras esportivas têm uma pequena participação (9\%) em futebol, bicicleta, corrida e pesca. Poucas são travessas (7\%). Algumas realizam atividades intelectuais, como cientistas, em estudos, leituras e ensino (34\%).

Os dados mostram que os meninos pouco participam das atividades domésticas (16\%), quando isso ocorre, cuidam de flores, plantas e/ou animais de estimação. Eles participam preferencialmente de atividades esportivas, jogam futebol, andam a cavalo, de bicicleta e pescam (52\%). Nas atividades externas, correm, vão à praia, brincam com terra, lama e água, carrinho e avião, empinam pipa e sonham viajar como astronauta (45\%). São mais travessos (48\%) do que as meninas. E no sentido intelectual, os meninos desenvolvem as mesmas atividades que as meninas, mas os dados apresentam uma freqüência maior (57\%) para eles.

Uma das imagens presentes em um dos livros estudados mostra algumas crianças brincando na sala. Um menino vestido de vermelho tenta pegar um balão no 
alto, para isso, apresenta-se com um pé na janela e outro sofá, mostrando risco de queda. Outro menino, vestido de camiseta branca e bermuda azul, segurando uma garrafa cheia de líquido, persegue uma menina vestindo vermelho e chiquinhas nos cabelos. Outro menino puxa o rabo de um cachorrinho que parece estar rosnando. Há também um garotinho ainda bebê, colocando o dedo na tomada de eletricidade. E uma menina aparentemente mais velha, vinda da cozinha, corre à sala para salvar a todos do caos instaurado. A imagem da cozinha, atrás dela, mostra um fogão e sobre ele uma panela.

Nessa imagem, a menina mais velha pode ser percebida como a mulher que cuida da prole e da alimentação. A menina que corre do menino, representa o lado frágil e ele, aquele que é forte, agressivo e dominador, igualmente ao menino que puxa o rabo do cachorro. O menino que tenta pegar o balão pode ser compreendido como o homem corajoso, independente, seguro e decidido. Estas características são as mesmas que durante muitos séculos foram consideradas como naturais da mulher e naturais do homem (SPARTI, 1995).

Em outra imagem estudada a menina localizada bem próxima à sua casa, veste um traje de estampa floral e joga bola com as mãos, tendo uma boneca ao seu lado. $\mathrm{O}$ menino, vestido de azul e usando boné, corre com os animais, longe de sua casa.

Os brinquedos das meninas, tais como a xicrinha e a panela, representam a vida no interior do lar. É observado nas obras, que as meninas em função da socialização para um determinado papel de gênero, brincam de atividades voltadas para as tarefas do lar e sustento do grupo doméstico, como cozinhar, lavar a louça, e cuidar de bonecas. O pensamento implícito nessa simbologia é que quando adultas, desenvolverão esse papel, logo, devem brincar com utensílios relacionados a essas atividades e estar sempre em espaços próximos ao lar. Essa idéia converge para o argumento de Carvalho (1999) e de Bock, Furtado e Teixeira (2001, p. 315) os quais afirmam que o papel atribuído culturalmente à mulher é o de ser amorosa, cuidar da prole e das tarefas domésticas.

Nos papéis difundidos pelos livros um ideal de maternidade é simbolizado pela boneca. Esta se apresenta como um paradigma do aprendizado infantil sobre os papéis de gênero fortemente marcados pela oposição de papéis femininos e masculinos; instituindo-se uma identidade de gênero, construída a partir de que tal identidade determinaria o exercício da sexualidade feminina.. 
As brincadeiras são apresentadas nas obras como diferenciador de gênero. A menina brinca bem próxima à sua casa, implicando a idéia de controle. Ela, em função do gênero, deve ser vigiada e regulada. Já o menino deve ser independente e aprender isso desde cedo. Certos brinquedos destinados ao menino, tais como a pipa e o cavalo, entre outros, representam o direcionamento a espaços externos e abertos. O menino deve ser levado a conhecer e dominar os espaços e ambientes mais distantes do lar, reproduzindo o que lhe é esperado quando crescer: ir pra rua em busca do sustento da família.

Os estudos de Bock, Furtado e Teixeira (2001, p.315) destacam que tradicionalmente e em função do papel que desempenharão quando adultas, as brincadeiras das meninas estão voltadas para o lar, ou seja, para a esfera privada e as brincadeiras dos meninos exigem tomadas de decisão, e estão voltadas para a rua, isto é, para a esfera pública.

Essa ideologia cria um contexto de hierarquia de poder, o qual implica que somente ao homem é dada a liberdade e a capacidade de produzir bens. De acordo com Sparti (1995, p. 15), independência, decisão, segurança, dominância e inteligência foram consideradas "naturalmente" atributos dos meninos. "Em suma, meninas e meninos são socializados de forma diferenciada e é "normal" que diante da vida, quando adultos, tenham posturas, ações e reações distintas".

No caso dos meninos, as tarefas e as brincadeiras revestem-se de uma categorização de masculino porque envolvem, segundo os sujeitos sociais, mais "peso", implicando a vigência do valor a ele atribuído, associado à concepção de que trabalho de homem envolve maior força física para ser executado.

Os brinquedos de meninos parecem estimular o percurso da investigação do desconhecido, seja através de um imaginário fantástico, seja através da ciência; ambas reconhecidas como ocupações naturalmente adequadas ao espírito aventureiro de meninos, podem ser percebidas como oposição entre o mundo do lar, estimulado como referência central para a menina, e o mundo dos estudos e da diversão, para o qual é voltado o menino.

Como aspecto positivo e de transformação das relações de gênero pode-se destacar a interação entre meninas e meninos em diversas obras (59\%). Eles brincam com água, jogam futebol, estudam, desenvolvem atividades escolares, brincam de roda, fazem coleta seletiva de lixo, pulam corda, se abraçam, sobem em árvores, 
merendam juntos e outras mais. Segundo Casagrande (2005), a representação da interação entre meninas e meninas a partir do mesmo tipo de brincadeiras "apresentase como uma excelente oportunidade para desconstruir a imagem de que existem brincadeiras para meninas e outras para meninos" em oposição entre feminino e masculino.

\section{O TRABALHO DE HOMEM E TRABALHO DE MULHER}

O gráfico 03 apresenta o resultado da análise dos dados considerando o trabalho na esfera pública e na privada, categorizados em: cuidado com as crianças, cuidado com a casa, cuidado com a alimentação, saúde (enfermagem, medicina, odontologia e veterinária) e educação (magistério).

Gráfico 03. Trabalho de homem e trabalho de mulher (amostra de 44 livros)

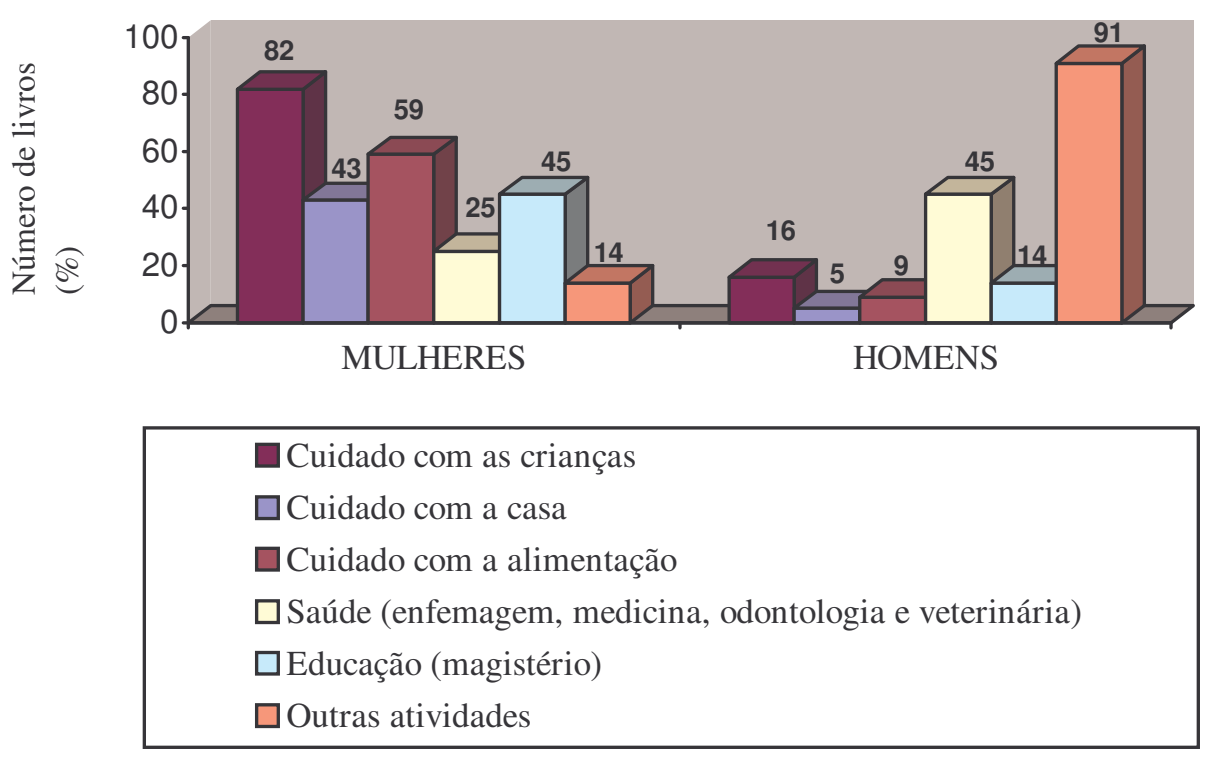

O exercício da sexualidade feminina estaria ligado à reprodução biológica e às atividades não remuneradas, realizadas para a manutenção e reprodução da força de trabalho. Segundo Louro (1995) e Scott, (1991) esse papel tem sido tradicionalmente atribuído às mulheres. A diferença se instala a partir desse trabalho reprodutivo, sendo que várias linhas interpretativas explicam estar na apropriação da fecundidade feminina pelo sexo masculino, a origem da desigualdade entre os gêneros, presentes em diversas sociedades (BARBIERI, 1991). 
Nas ilustrações dos livros, essas idéias são acentuadas na relação do trabalho de homem e do trabalho de mulher. O homem pesca, lava e dirige o carro - tudo o que está relacionado com carro relaciona-se com homens, implicando na idéia de que mulheres não podem dirigir. A mulher cuida de casa (43\%), lava e estende roupas no varal, passa roupa, cuida da alimentação (59\%), segura panela, lava pratos, cozinha e serve a mesa. Ela é representada, nos livros, pela típica dona de casa que cuida das crianças $(82 \%)$ e do marido. Estes resultados também condizem com as discussões de Rocha-Coutinho (1994), de que socialmente é atribuída à mulher a característica de cuidadeira, "refletida nas suas atuações como mãe, esposa e dona-de-casa" (CAIXETA; BARBATO, 2004, p. 214).

As mulheres também podem ser professoras (45\%), trabalhar na área da saúde (25\%) como enfermeiras e algumas poucas odontólogas. Nas exceções, a mulher é apresentada como: executiva, catadora de papel, costureira, vendedora, cientista, artista plástica e técnica de futebol infantil (14\%). Quando não desempenham esses papéis, elas não desempenham mais nenhum outro, pois simplesmente não aparecem nas imagens dos livros analisados.

Pode-se perceber o homem no espaço privado cuidando das crianças através do diálogo (16\%), ajudando nas tarefas do lar (5\%), e principalmente, cuidando do jardim. Os homens também se voltam para a preparação da alimentação (9\%), dentre eles $5 \%$ são panificadores ou mestres e $4 \%$ ou preparam o alimento em casa ou vão à feira, isso mostra que o "preparar alimentos" para os homens, diferente da mulher, também se insere no espaço público.

Destaca-se a sustentação de modelos estereotipados do masculino e feminino nos livros didáticos; neles, as professoras de crianças menores são mulheres. Já a atividade de docência executada pelos homens (14\%) é voltada para crianças maiores e em áreas como matemática, física, biologia e geografia.

É importante ressaltar as diferenças de status dessas profissões, determinadas pela sociedade. A partir do momento que a mulher entra no mercado de trabalho, a profissão (qualquer que seja) ocupada por elas passa a ser desvalorizada em comparação àquela ocupada exclusivamente pelos homens (BOURDIEU, 1999). Justifica-se, assim, a desvalorização do magistério, ocupação considerada do gênero feminino e executada por mulheres; especialmente quando é voltado para a educação de crianças menores. Na educação, também persiste a tendência de diferenciação entre 
homens e mulheres nas trajetórias escolares; os homens dirigindo-se às áreas das ciências exatas e engenharias e as mulheres às ciências humanas, letras e artes.

O que se estabelece são normas da segregação sexual entre ambos. De acordo com Costa (1994) e Rocha-Coutinho (1994), a diferença entre gêneros impõe diferenças morais aos comportamentos feminino e masculino, conforme as exigências da sociedade capitalista e individualista.

A distribuição das tarefas entre os sexos é, em muitos sistemas culturais, entendida como uma espécie de extensão das diferenças anatômicas (ou procriativas) entre os sexos (GRACIANO, 1975). Assim, parece "natural" ser compatível ao sexo feminino uma série de tarefas associadas ao papel que a mulher ocupa no processo reprodutivo. $\mathrm{O}$ cuidado com a prole é sempre destinado às mulheres, mas este se situa para além do papel propriamente reprodutivo. Todavia, recebe uma carga simbólica de atributo pré-social da condição feminina. Então, ideologicamente, as mulheres estariam representadas mais presas ou imersas no plano natural do que os homens (DURHAM, 1983, p.15).

Quando a abordagem é profissão, os livros estudados caracterizam de forma muito clara, as femininas e as masculinas, veiculando uma divisão sexual do trabalho. Atribuem de forma diferenciada as tarefas que se faz, a partir das capacidades estabelecidas convencionalmente, aos homens e às mulheres. Nota-se também a ideologia do trabalho (ROMANELLI, 1993) como um dos marcos definidores da identidade masculina e da identidade feminina.

Assim, o papel produtivo referente à realização de atividades executadas em troca de remuneração, dinheiro ou mercadoria, é atribuído aos homens, cabendo-lhes a responsabilidade de prover os recursos do lar. Já à mulher cabe a responsabilidade pela reprodução e pelas atividades da casa. Este posicionamento das obras analisadas está de acordo com as discussões teóricas de Rocha-Coutinho (1994).

No Brasil, esse modelo de família, implícito ainda hoje em muitas políticas públicas, tem se modificado cada vez mais. As estatísticas mostram que a participação feminina no mercado de trabalho vem aumentando gradativamente. Incorporando a essa análise, têm-se os dados divulgados pelo IBGE para a PNAD-2004, que apresentam o nível de ocupação das mulheres. Eles mostram um índice de 45,5\% da população ativa constituído de mulheres, e um incremento da participação feminina no mercado de trabalho: “A contribuição feminina (1,5 milhão de mulheres) no aumento do número de pessoas ocupadas foi superior à da masculina (1,1 milhão de homens)". 
Cresce também, segundo o IBGE, o número de famílias cuja renda principal vem do trabalho da mulher.

Mesmo com essa participação da mulher no mercado de trabalho, e o seu desempenho simultâneo dos papéis reprodutivo e produtivo, as desigualdades de gênero permanecem. Embora as mulheres tenham em média mais anos de estudo que os homens, ainda participam menos da população economicamente ativa (IBGE, 2004); têm menos acesso a postos de decisão; são excluídas de certas ocupações compatíveis com sua biologia e, pelo mesmo trabalho, recebem remuneração inferior a dos homens. Dados dessa mesma pesquisa mostram que em 2004, a remuneração média das mulheres trabalhadoras representava $69,3 \%$ do valor recebido pelos homens, pela mesma função exercida. Praticamente não houve mudança de patamar em relação a 1999, quando a percentagem era de 69,1\%.

A antiga mãe e esposa, circunscrita à esfera privada ou do lar, deu lugar a outra mulher que além daquelas responsabilidades, está no mercado de trabalho em busca de reconhecimento e remuneração igualitária, ainda atuando para garantir o acesso da comunidade aos bens de consumo coletivos. Tais transformações alteram os papéis e as necessidades não só das mulheres, mas também dos homens.

\section{PAPÉIS MASCULINOS E PAPÉIS FEMININOS}

Para estudiosos como Graciano (1978), Rocha-Coutinho (1994), Louro (1995) e Scott (1991), as sociedades institucionalizam a segregação sexual estabelecendo diferenças entre o papel do homem e o da mulher. Percebe-se que as atribuições sociais de cada sexo, veiculadas nos livros, são definidas de tal forma que a delicadeza feminina é colocada em oposição à dureza masculina e, ao dar ao homem um caráter ativo, concede-se à mulher, automaticamente, um caráter passivo; se o homem é duro, a mulher é suave, doce e meiga.

Tal antagonismo é evidente nos livros didáticos, pois enquanto o homem corta as árvores com machado, a mulher rega o jardim cultivando flores; enquanto o homem joga lixo nos rios, a mulher enfeita a casa; enquanto o homem mata os animais em caçadas, a mulher alimenta o cachorrinho; enquanto o homem polui o ar com cigarro, carro e indústrias, a mulher brinca com as crianças na pracinha, rodeada de flores. E assim por diante. 
O homem presente nos livros, é o que vive o papel de gênero tradicional; é o provedor do lar, típico pai de família, pouco participativo, quem define e executa tarefas convencionalmente masculinas. De acordo com Badinter (1996), esse tipo de homem é identificado na atualidade, como o homem duro ou o masculino. Para tal homem, um conjunto de atitudes e comportamentos pode ser atribuído na sua identificação. Tais comportamentos podem ser acompanhados de estereótipos, nem sempre positivos, como os adjetivos forte, autocrítico, racional, aventureiro, dominador, rude, agressivo, decidido, competitivo, menos afetivo e mais "durão", assertivo, desafiador, orientado para a realização, e silencioso.

O poder do homem é então, entendido - bem apontou Ramirez (1989) - como respeitabilidade, autoridade, invulnerabilidade, força. Desse modo, no modelo de masculinidade a ser seguido nos livros, destacam-se as idéias de que o homem de verdade é solitário, reservado e prático, voltado para agir e realizar atividades.

Em confronto com esse modelo, a sociedade de hoje espera que o homem compreenda as demandas emocionais de suas parceiras e de seus filhos, sendo cúmplice e sensível ao mesmo tempo. Nas palavras de Ortiz (1995, p.151) "o poder masculino, que representa, definitivamente, certos privilégios para o homem nas sociedades patriarcais, também significa angústia e muita solidão existencial". E ainda, segundo Ramirez (1989), fazer-se homem é processo difícil e doloroso, que o converte em seu próprio opressor.

As tensões que surgem nas relações íntimas entre os gêneros, entre a manutenção do poder do macho e a possibilidade de viver novos modelos de masculinidade, nos quais se contempla a associação entre sexo, afetividade e um relacionamento igualitário com a parceira amorosa, têm sido um dos motivos para se falar de uma crise masculina.

A crise da masculinidade, para Nolasco (1997), em parte está associada a valores sociais que transcendem a dimensão do indivíduo. Caracteriza-se pela tentativa de homens se diferenciarem do padrão de masculinidade estabelecido socialmente para eles. Manifestam-se então, outros tipos de homens, como o homem mole ou homem doce, o qual, para Badinter (1996), é aquele que renuncia voluntariamente aos privilégios masculinos (poder e superioridade do macho) sendo partidário da igualdade entre homem e mulher. Este é um tipo de homem participante e sensível, que mantém a masculinidade, admitindo sua sensibilidade. Segundo a mesma autora, há também o não-masculino. No oposto do eixo dos contraditórios, 
seria o tipo que apresenta características femininas. Hipoteticamente, um homem que não se importa em aparentar e provar sua masculinidade.

Consequentemente, a abordagem que procura ressaltar a perspectiva de gênero não deve se preocupar exclusivamente com a condição feminina, ou com as experiências e percepções das mulheres, mas sim com a atribuição de papéis, recursos, responsabilidades e expectativas relativas a homens e mulheres. Nas relações de gênero "nenhuma compreensão de qualquer um dos dois pode existir através de um estudo que os considere totalmente em separado" (SOIHET, 1997, p.101).

O convite é para que todos aceitem reaprender a olhar tais atributos, tornando visíveis - portanto passíveis de avaliação crítica - as relações que eles expressam. Nesse trabalho, ao adotar um ponto de vista que valoriza a busca de maior igualdade, são colocadas em questionamento todas as idéias preconcebidas, tanto as que dizem respeito à mulher quanto ao homem, faces da mesma moeda.

\section{CONSIDERAÇÕES FINAIS}

Os livros analisados podem contribuir para a orientação da identidade sexual das crianças, visto oferecerem símbolos e recursos usados para criar uma cultura comum, situando os indivíduos na sociedade. Trazem textos sociais voltados para o desenvolvimento da percepção do que é ser mulher e do que é ser homem, sugerindo formas de pensar e de agir, criando, intrinsecamente, sugestões que podem ser processadas ativamente pelos alunos, de acordo com suas experiências pessoais.

Apesar de todos os progressos alcançados pelas mulheres nas últimas décadas, os resultados quanto aos papéis de gênero, não diferem dos achados nos estudos de décadas anteriores a esta. Os estudos sobre livros didáticos, revisados aqui, sugerem que a identidade feminina está subordinada em favor da dominação masculina. Desta forma, estes livros podem contribuir para o controle patriarcal das vidas femininas, reforçando, a partir das relações de gênero, as condições que legitimam as estruturas de poder existentes.

Em um grande número de livros didáticos, as mensagens subliminares trazidas nas imagens, ainda mostram o menino como protagonista e a menina como 
coadjuvante, oferecendo aos meninos a possibilidade de liberdade, de poder; às meninas um papel social subordinado e secundário.

Em oposição a essas ideologias, existe no mundo contemporâneo, uma diversidade de culturas e crenças, de identidades psicológicas, sociais, sexuais e de gênero, que torna impossível uma concepção hegemônica frente às nossas próprias identidades, as quais não são fixas e imutáveis. Ao contrário, sofrem mudanças constantes e, a cada década que passa, podemos perceber com mais intensidade que a cultura, os modos de vida, de se comportar, de ser e de estar, vão se alterando, adequando-se às exigências do próprio tempo.

Neste contexto, é necessário reforçar as idéias e valores que não destacam a concepção de um mundo masculino superior ao feminino e que, ao contrário, estabeleçam condições de igualdade de oportunidades para ambos os sexos. Não se trata de formar as meninas à imagem e semelhança dos meninos, mas, segundo Sparti (1995, p. 19), restituir à pessoa "a possibilidade de desenvolver-se do modo que mais lhe convém, independentemente do sexo a que pertence".

A identidade de gênero e a identidade sexual são passíveis de mudanças. Em muitos livros nota-se a busca da transformação dos conceitos que envolvem a (re)construção dessas identidades. Esse posicionamento educacional é benéfico para a sociedade. Os primeiros passos estão sendo dados, mas compreendendo os processos históricos da formação das relações entre homens e mulheres, acredita-se que a mudança não será rápida e nem fácil, mas os benefícios compensarão as dificuldades.

Para se combater a educação sexista deve-se fazer leituras críticas dos livros didáticos, a partir da perspectiva de gênero, pois apesar deste trabalho se referir somente as coleções da área de Ciências, há inferências de que o mesmo ocorre nas outras áreas de ensino das primeiras fases da educação escolar. Deve-se também analisar a realidade da sociedade brasileira e os papéis atuais do homem e da mulher na sociedade contemporânea. Também há necessidade de reflexão sobre gênero em nossas práticas e instituições sociais, e nessa perspectiva, é preciso potencializar a escola como um espaço de educação não-sexista, voltado para a superação de preconceitos entre os sexos.

Os livros podem ser ilustrados de modo a representar os gêneros numa perspectiva mais relacional, mostrando um homem menos tradicional e provedor e uma mulher mais participativa do mercado de trabalho, que também produza bens e 
tenha uma ação política. Podem contemplar a multiplicidade de relações entre os gêneros no lugar de apresentar um único padrão sobre o que é ser homem e o que é ser mulher.

Para Giroux (1995, p. 100), professores e professoras se constituem como produtores de cultura. Sendo assim, no que se refere às relações de gênero, os educadores devem ultrapassar seus papéis de transmissores de informação; devem estar sempre em formação continuada, revendo seus conceitos e preconceitos, capacitando-se a perceber as visões estereotipadas nos materiais didáticos, sejam eles livros ou outros quaisquer; "devem estar conscientes e entender o poder e influência de seu comportamento e atitudes, assim como do que ensinam e de como ensinam" (WHITELAW, 2003, p. 38) na formação integral das/os alunas/os. 


\section{REFERÊNCIAS BIBLIOGRÁFICAS}

BADINTER, E. XY. A identidade masculina. Lisboa: ASA, 1996

BARBIERI, Teresita de. Sobre la categoría de género - una introducción teórico metodológica. In: AZEREDO, Sandra, STOLCKE, Verena (Coords.). Direitos reprodutivos. São Paulo: Fundação Carlos Chagas, 1991. p.25-45.

BAUDRILLARD, J.. A troca semiótica e morte. São Paulo: Loyola, 1996.

BIOCCA, F. Opposing conceptions of the audience: The active and passive hemispheres of mass communication theory. In ANDERSON, J.A. (ed.).Coummunication Yearbook 11. Sage, Beverly Hills, CA, 1988.

BOCK, A M. B., FURTADO, O. ; TEIXEIRA, M. L. T. Psicologias: Uma introdução ao estudo da psicologia. 13. ed., São Paulo: Saraiva, 1999.

BOURDIEU, P. A. A dominação masculina. Rio de Janeiro: Bertrand Brasil, 1999.

BRASIL - Secretaria de Educação Fundamental. Parâmetros Curriculares Nacionais: Ciências Naturais. S.E.F. Brasília: MEC/SEF, 1998.

Parâmetros Curriculares Nacionais: primeiro e segundo ciclos. apresentação dos temas transversais. S.E.F. Brasília: MEC/SEF, 1998.

CASAGRANDE, L. S.; Educando AS novas gerações: representações de gênero nos livros didáticos de Matemática. 2005. Dissertação (mestrado em Tecnologia) Programa de Pós Graduação Tecnológica, Centro Federal de Educação Tecnológica do Paraná, Curitiba. Disponível em: http://www.ppgte.cefetpr.br/dissertacoes/2005/ casagrande.pdf.

CARVALHO, M. P. No coração da sala de aula: gênero e trabalho docente nas séries iniciais. São Paulo: Xamã, 1999.

CAIXETA, J. E.; BARBATO, S. Identidade feminina: um conceito complexo. Paidéia: cadernos de psicologia e educação, São Paulo, v. 14, n. 28, p. 211-220. maio/ago. 2004.

COSTA, Jurandir Freire (org.). Redescrições da Psicanálise: ensaios pragmáticos. Rio de Janeiro: Relume-Dumará, 1994.

CURRIE, DAWN H. Girl Talk: Adolescent Magazines and Their Readers. Toronto, University of Toronto Press, 1999.

DURHAM, Eunice R. Família e reprodução humana. In: PERSPECTIVAS antropológicas da mulher. v.3, Rio de Janeiro: Zahar, 1983. p.13-44.

EMBACHER, A.. Moda e identidade: a construção de um estilo próprio. São Paulo: Anhembi Morumbi, publicado 2003.

FEIJÓ, Bruno Vieira. Revista Superinteressante, São Paulo, n. 212, abr. 2005.

FISCHER-MIRKIN, T.. O código do vestir: os significados ocultos da roupa feminina. Trad. Ângela Melim. Rio de Janeiro: Rocco, 2001. 
GRACIANO, M.. Aquisição de papéis sexuais na infância. Cadernos de Pesquisa, n.25, p. 29-44, jun. 1978 .

Contribuições da psicologia contemporânea para a compreensão do papel da mulher. Cadernos de Pesquisa, n.15, p.145-150, dez. 1975.

GIROUX, H. McLAREN, P. Por uma pedagogia crítica da representação. In: SILVA, T. T.; MOREIRA, A F. (org.). Territórios contestados: o currículo e os novos mapas políticos e culturais. Petrópolis: Vozes, 1995.

HALL, S. Cultural identity and diaspora. In RUTHERFORD, J. (ed.). Identity, community, culture, difference. London: Lawrence and Wishart, 1990.

A identidade Cultural na Pós-Modernidade. Tradução de Tomaz Silva e Guacira Louro. Rio de Janeiro: DP\&A, 2002

IBGE. Pesquisa Nacional por Amostra de Domicílios 2004. Disponível em: $<$ http://www.ibge.gov.br/home/presidencia/noticias/noticia_visualiza.php?id_noticia= 487\&id_pagina=1>. Acesso em: 01 abr 2005.

LOURO, G. L. Gênero, história e educação: construção e desconstruçao. Educação $\boldsymbol{e}$ Realidade, 20 (2), p. 101-132, 1995.

Gênero Sexualidade e Educação: uma perspectiva pós-estruturalista. Rio de Janeiro: Vozes: Vozes, 1998.

NOLASCO S. Um homem de verdade, In: CALDAS, D. (org.). Homens. São Paulo: Senac, 1997. p. 13-29.

NOSELLA, M.L.C.D. As belas mentiras: A ideologia subjacente aos textos didáticos. São Paulo, Cortez e Moraes, 1979. (Educação Universitária).

ORTIZ, R.. "Discursos masculinos: auto-opressão da transmissão de HIV/AIDS". In: NOLASCO, I.. A desconstrução do masculino. Rio de Janeiro: Rocco, 1995. p. 14855.

RAMÍREZ, R.L. Ideologias masculinas, sexualidad y poder. Relatório apresentado no XII Congreso de la Sociedad Interamericana de Psicologia. Buenos Aires, 1989.

ROCHA-COUTINHO, M. L. Tecendo por trás dos panos: a mulher brasileira nas relações familiares. Rio de Janeiro: Rocco, 1994.

ROMANELLI, G. Familias de classes populares: sociedade e identidade masculina. Ribeirão Preto: USP, 1993.

SCOTT, J.. Gênero: Uma categoria útil para a análise histórica. Trad. Christine Rufino Dabat e Maria Betânia Ávila Recife: SOS Corpo. 1991.

SOIHET, R. História, mulheres, gênero: contribuições para um debate. In: AGUIAR, Neuma (org.). Gênero $\boldsymbol{e}$ Ciências Humanas: desafios às ciências desde a perspectiva das mulheres. Rio de Janeiro: Record/Rosa dos Tempos, 1997.

SPARTI, S. C. M. Construindo a identidade masculina e feminina. Revista de estudos universitários. v. 21, n. 1. Sorocaba, p. 9-20, jun. 1995. 
SPENCE, J. T.. Gender-related traits and gender ideology: Evidence for a multifactorial theory. Journal of Personality and Social Psychology, n.64, p. 624635. 1993

WHITELAW, S. Questões de Gênero e eqüidade na formação docente. In: CARVALHO, M. E. e PEREIRA, M. Z. C. (org.). Gênero e Educação: Múltiplas faces. João Pessoa: Editora Universitária/UFPB, 2003. p. 33-44. 